\title{
Model Reservoir Formasi Woniwogi Blok "FRD", Cekungan Akimeugah Menggunakan Metode Seismik Multiatribut
}

\author{
Fitri Rusmaladewi ${ }^{*}$, Sugeng Sapto Surjono and Djoko Wintolo
}

\begin{abstract}
Ringkasan
Cekungan Akimeugah merupakan salah satu cekungan yang berpotensi adanya kandungan minyak dan gas bumi. Daerah penelitian, Blok "FRD" berada di lepas pantai sebelah utara Laut Arafura. Top Formasi Woniwogi menjadi batas atas penelitian dan Top Formasi Kopai menjadi batas bawah penelitian. Tujuan dari penelitian ini untuk mengkarakterisasi reservoir dan menentukan zona prospek pada daerah penelitian. Penelitian ini menggunakan data 3 sumur (FRD1, FRD2 dan FRD3) dan data seismik 26 lintasan 2D PSTM untuk pengolahan seismik multiatribut. Metode ini digunakan untuk memprediksi beberapa properti fisik dari bumi dengan menggunakan lebih dari satu atribut. Pengolahan data diawali dengan identifikasi well seismic tie, picking horizon dan picking patahan, membuat peta bawah permukaan, inversi seismik dan multiatrbut. Software yang digunakan yaitu Hampson Russel 8 dan Petrel 2015. Dari hasil inversi dan multiatribut, Formasi Woniwogi sumur FRD1 ini memiliki nilai impedansi akustik rendah $20.000-26.500((\mathrm{ft} / \mathrm{s}) /(\mathrm{g} / \mathrm{cc}))$, nilai gamma ray rendah sampai sedang $70-150 \mathrm{API}$, dan nilai porositas efektif tinggi $6-8 \%$. Dari hasil tersebut, sumur FRD1 pada Formasi Woniwogi dapat diinterpretasikan sebagai potensial reservoir hidrokarbon.
\end{abstract}

Kata Kunci : Formasi Woniwogi, Cekungan Akimeugah, Hidrokarbon, Inversi Seismik, Multiatribut Seismik.

\begin{abstract}
Akimeugah Basin is one of the potential oil and gas basins. The research area called "FRD" Block is located in Akimeugah Basin, in the northern part of Arafura Sea offshore. The research area boundary is Top Woniwogi Formation until Top Kopai Formation. The Wonowogi Formation is one of hydrocarbon potential formation. The main purpose of this research is reservoir characterization and prospect zone determination in the research area. The research will integrate 3 wells data (FRD1, FRD2, and FRD3) and 26 trace 2D PSTM with multiattribute seismic. The multiattribute seismic is to predict several physical properties from the earth with more than one attribute. The data processing starts with well seismic tie, picking horizon, picking fault, subsurface mapping, inversion and multiattribute seismic. The processing data will use Hampson Russel 8 and Petrel 15. The result of inversion and multiattribute at FRD1 has low acoustic impedance value $20,000-26,500((\mathrm{ft} / \mathrm{s}) /(\mathrm{g} / \mathrm{cc}))$, low until intermediate gamma ray value $70-150 \mathrm{API}$, high effective porosity value $6-8 \%$. Based on that, so the FRD1 well in Woniwogi Formation interpreted as the potential hydrocarbon reservoir.
\end{abstract}

Keywords: Woniwogi Formation; Akimeugah Basin; Hydrocarbon; Seismic Inversion; Seismic Multiattribute.

\section{PENDAHULUAN}

Cekungan Akimeugah merupakan salah satu cekungan di Indonesia yang berpotensi besar memiliki kandungan minyak dan gas bumi. Cekungan Akimeugah terdiri dari beberapa blok yang berada di

\footnotetext{
${ }^{*}$ Correspondence: fitrirusmala.FRD@gmail.com

Departemen Teknik Geologi, Fakultas Teknik, Universitas Gadjah Mada,

Yogyakarta, Indonesia

Full list of author information is available at the end of the article

${ }^{\dagger}$ Equal contributor
}

darat maupun di lepas pantai. Blok "FRD" merupakan salah satu blok yang masih dalam tahapan eksplorasi lepas pantai yang akan menjadi fokus pada penelitian ini. Blok ini terdiri dari beberapa formasi yang menyusunnya, salah satunya yaitu Formasi Woniwogi yang diketahui adanya potensi hidrokarbon. Iqbal dan Sugeng (2017) [1] membuktikan bahwa pada formasi ini mempunyai porositas $10-20 \%$. Formasi ini berumur Mesozoikum (Jura Akhir sampai Kapur Awal) dengan ketebalan \pm 200 meter yang 
terdiri dari batupasir kuarsa glaukonitik, batuserpih, abu-abu sampai hitam batulumpur mika, batulumpur glaukonitik, dan lumpuran batulanau [2]. Untuk mengetahui karakteristik reservoir Formasi Woniwogi yang diduga terdapat potensi hidrokarbon, penulis melakukan penelitian menggunakan metode seismik multiatribut.

Metode seismik multiatribut adalah suatu hubungan antara data log pada sumur dengan data seismik yang menggunakan lebih dari satu atribut untuk memprediksi beberapa properti fisik bumi. Pada metode ini juga dilakukan validasi yang bertujuan untuk menentukan kebenaran jumlah atribut yang digunakan [3]. Metode ini diharapkan mampu membantu penulis untuk mengetahui kondisi reservoir dan menentukan zona prospek hidrokarbon pada daerah penelitian.

\section{METODE PENELITIAN}

Lokasi penelitian, Blok "FRD" berada di lepas pantai sebelah utara Laut Arafura. Penelitian ini menggunakan data seismik 2D PSTM sebanyak 26 lintasan, 3 sumur yaitu FRD1, FRD2, dan FRD3 yang mempunyai data log lengkap serta data checkshot, data pengeboran, dan data laporan sumur. Software yang digunakan yaitu Hampson Russell 8 dan Petrel 15. Pengolahan data diawali dengan identifikasi data log pada sumur, well seismic tie, identifikasi data seismik, picking horizon dan picking patahan, inversi seismik dan multiatribut.

Analisis seismik multiatribut adalah salah satu metode statistik menggunakan lebih dari satu atribut untuk memprediksi beberapa properti fisik dari bumi. Pada analisis ini dicari hubungan antara log dengan data seismik pada daerah lokasi sumur dan menggunakan hubungan tersebut untuk memprediksi atau mengestimasi volume seismik dari properti log. Validasi merupakan parameter untuk menentukan kebenaran jumlah atribut yang digunakan [3]. Terdapat beberapa klasifikasi atribut yang dapat digunakan pada metode seismik multiatribut. Klasifikasi ini menurut Brown (2000) [4] yang membagi berdasarkan kategori waktu, amplitudo, frekuensi, dan atenuasi yang mana dikelompokkan ke dalam post stack dan pre stack pada sub kategori (Gambar 1). Informasi yang dapat diekstrak dari pengukuran khas atribut seismik, yaitu fitur geometri, kinematik, dinamik, dan statik.

\section{HASIL DAN PEMBAHASAN}

\subsection{Well Seismic Tie}

Tujuan well seismic tie (WST) yaitu mengikat data seismik dengan data sumur. Sumur yang

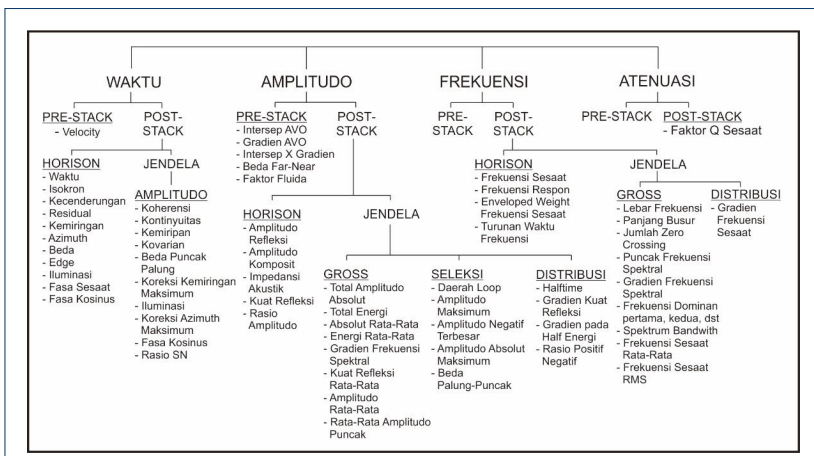

Gambar 1: Klasifikasi atribut seismik [4].

dilakukan proses WST yaitu sumur FRD1 dan FRD2 dikarenakan sumur tersebut yang mempunyai data checkshot untuk mendukungnya. Wavelet yang digunakan yaitu ricker. Hasil korelasi dari WST sumur FRD1 yaitu 0,586 dan sumur FRD2 yaitu 0,769 (Gambar 2).

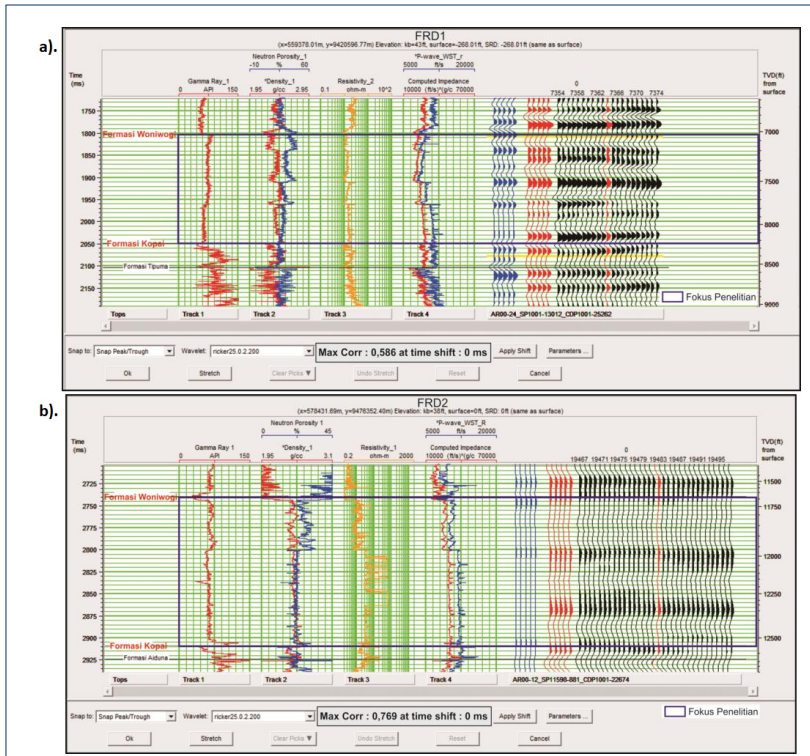

Gambar 2: Hasil WST a) FRD1 dengan nilai korelasi 0,586 dan b) FRD2 dengan nilai korelasi 0,769

\subsection{Picking Horizon dan Picking Patahan}

Picking horizon dilakukan pada marker Top Formasi Woniwogi sebagai batas atas dan Top Formasi Kopai sebagai batas bawah. Picking ini dilakukan secara menerus pada setiap penampang seismik dengan mengikuti bentuk wiggle. Picking patahan dilakukan apabila pada penampang seismik terjadi penurunan, biasanya wiggle menunjukkan perbedaan pada daerah 
yang terdapat patahan/struktur. Patahan yang terjadi biasanya menerus, dari satu penampang seismik ke penampang seismik selanjutnya. Hasil picking horizon dan picking patahan dapat dilihat pada Gambar 3.

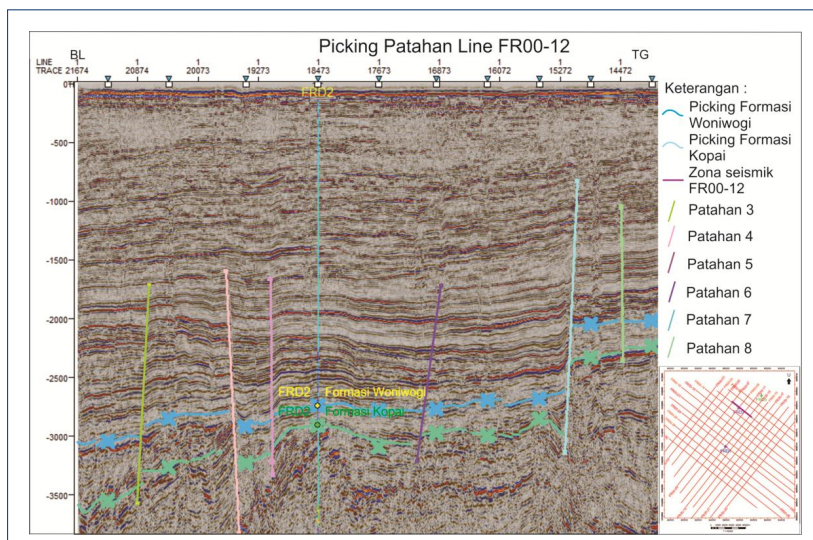

Gambar 3: Hasil picking horizon dan picking patahan pada FR00-12 dan sumur FRD2.

\subsection{Inversi Seismik}

Inversi seismik adalah suatu proses untuk menghitung model impedansi bawah permukaan yang sesuai dengan penampang seismik. Model awal dibuat untuk mengontrol hasil inversi, model ini dibuat dengan menggunakan data sumur dan data seismik. Tipe model awal yang dibuat yaitu inversi impedansi akustik (AI). Hasil inversi seismik dapat dilihat pada Gambar 4. Hasil inversi ini dikorelasikan dengan log impedansi. Nilai impedansi akustik pada Formasi Woniwogi berkisar $20.000-26.500$ ((ft/s)/(g/cc)), hal ini menunjukkan nilai impedansi akustik yang rendah.

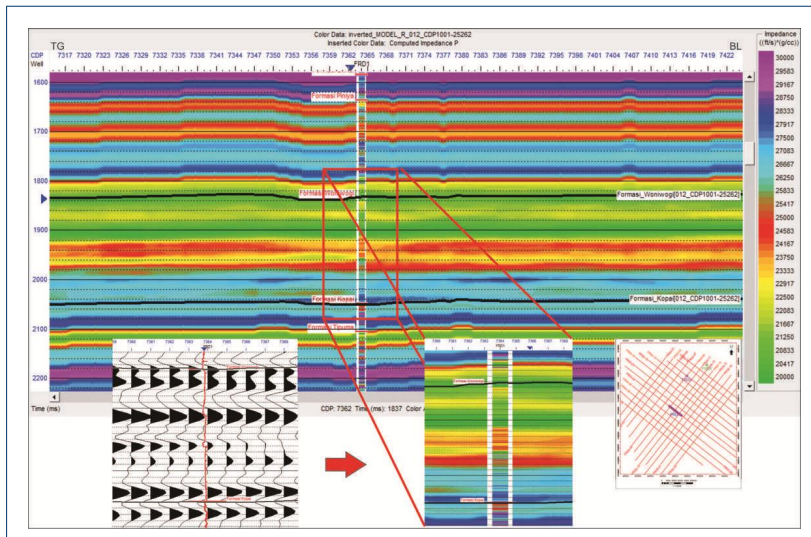

Gambar 4: Hasil inversi model based AI.

\subsection{Multiatribut Seismik}

Untuk mendapatkan hasil penelitian dan interpretasi yang lebih baik, maka dilakukan analisis multiatribut untuk menyebarkan properti batuan dari data log sumur. Multiatribut merupakan suatu metode untuk menganalisis data seismik dan beberapa atribut untuk memprediksi reservoir dan menyebarkan keseluruh cube seismik [3]. Penulis terlebih dahulu membuat daftar atribut yang paling baik yang akan digunakan dalam memprediksi log gamma ray lalu dikorelasikan dengan data seismik dan data inversi AI. Data atribut dan data seismik sebagai data internal dan data inversi AI sebagai data eksternal.

Penulis membuat lebar operator sebanyak 5, hal ini dilakukan untuk mendapatkan nilai error yang terendah dan yang dipilih untuk proses selanjutnya. Berdasarkan Gambar 5a grafik lebar operator 1 (warna hitam) memiliki nilai error terendah dibanding dengan grafik yang lain, maka grafik ini yang dipilih untuk proses membuat daftar atribut. Gambar 5b menunjukkan grafik korelasi (warna hitam) dan validasi (warna merah). Terlihat pada grafik validasi naik pada penambahan atribut ke-3, sehingga atribut yang digunakan hanya 2 atribut. Gambar 5c merupakan daftar atribut yang dipakai pada proses multiatribut gamma ray. Atribut yang dipakai yaitu atribut kecepatan rata-rata (AI) dan integrasi (AI).

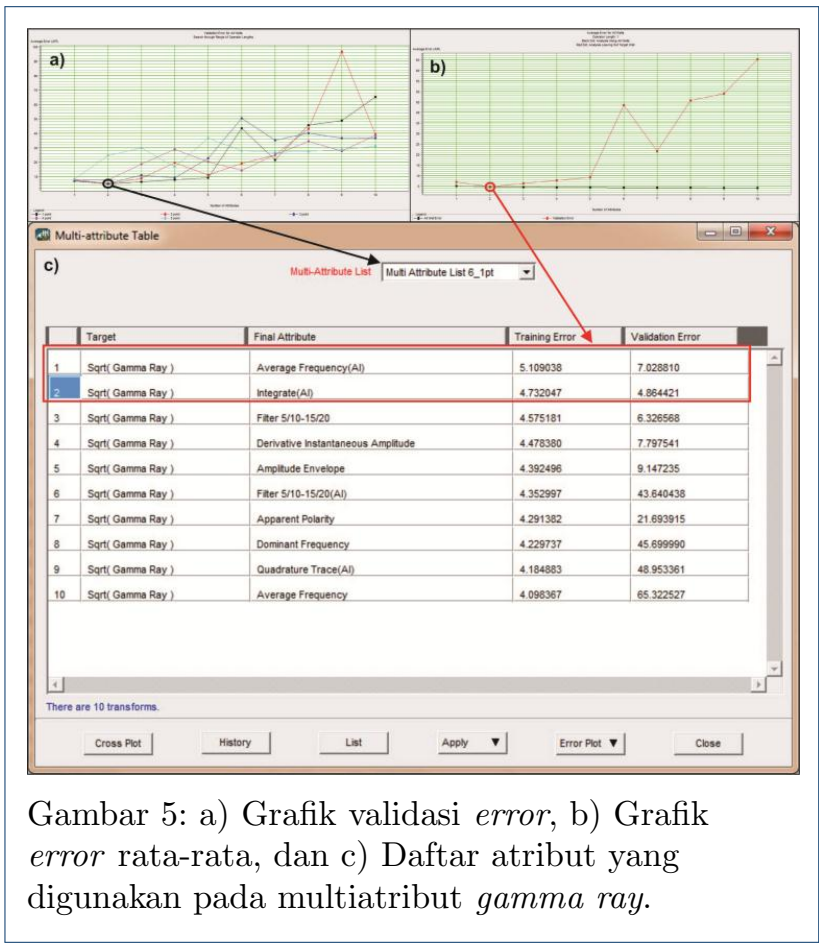

Setelah mengetahui jumlah atribut yang dipakai, penulis melakukan training dan validasi. Proses ini merupakan proses untuk mengetahui seberapa baik atribut ini digunakan untuk disebarkan ke cube seismik. Gambar 6 menunjukkan hasil training dan validasi. Hasil training dengan nilai korelasi 0,69262 
dan hasil validasi dengan nilai korelasi 0,67368. Hasil korelasi muliatribut gamma ray sudah cukup baik dan bisa disebarkan ke cube seismik. Hasil yang tepat dapat dilakukan dengan melihat kesesuaian log dengan hasil multiatribut (Gambar 7).

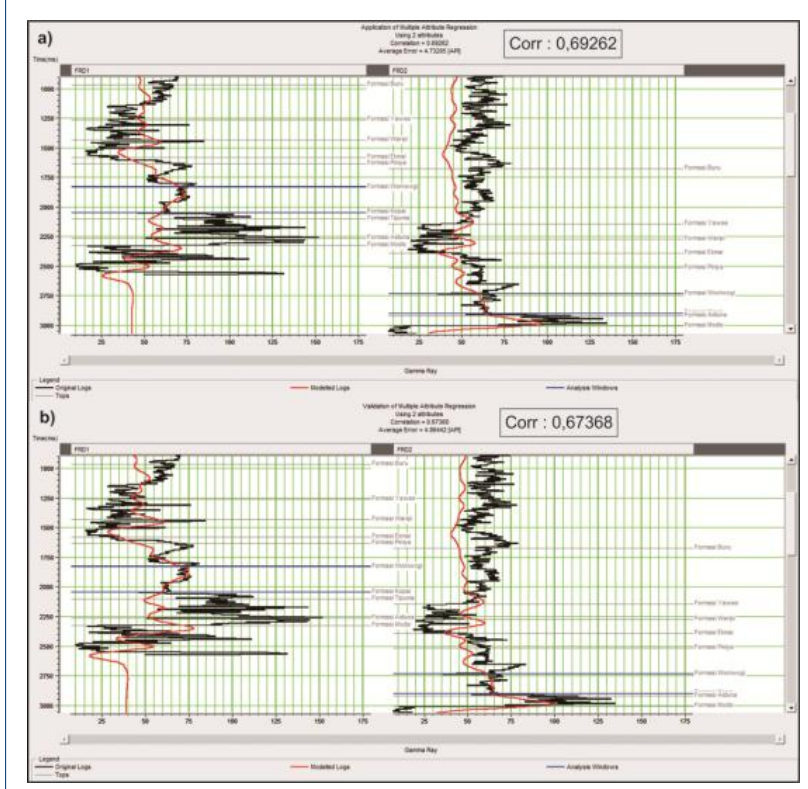

Gambar 6: Hasil training dan validasi.

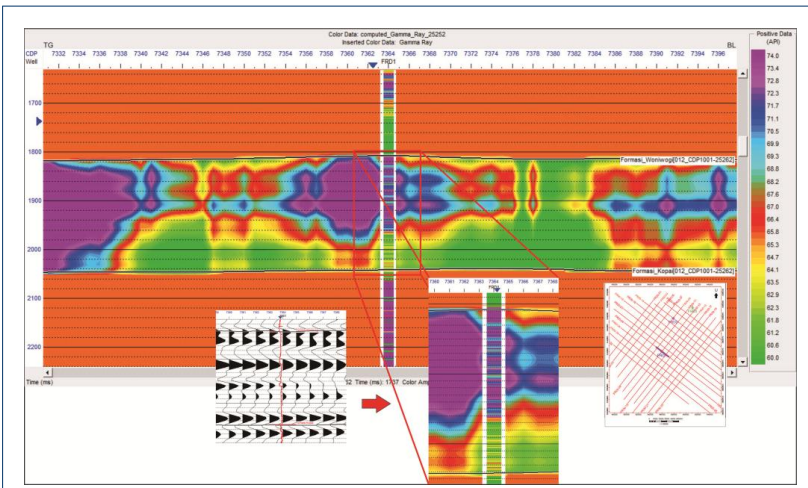

Gambar 7: Hasil validasi penyebaran multiatribut gamma ray dengan nilai log gamma ray.

Proses yang dilakukan untuk multiatribut porositas sama seperti yang dilakukan dalam analisis multiatribut gamma ray. Nilai porositas yang digunakan yaitu porositas efektif. Namun penulis tidak melakukan perhitungan langsung, data yang didapatkan dari perusahaan. Berdasarkan Gambar 8a grafik lebar operator 2 (warna merah) memiliki nilai error terendah dibanding dengan grafik yang lain. Gambar 8b menunjukkan grafik korelasi (warna hitam) dan validasi (warna merah). Gambar 8c merupakan daftar atribut yang dipakai pada proses multiatribut porositas. Atribut yang dipakai yaitu atribut integrasi (RHOB) dan atribut $P$ wave.

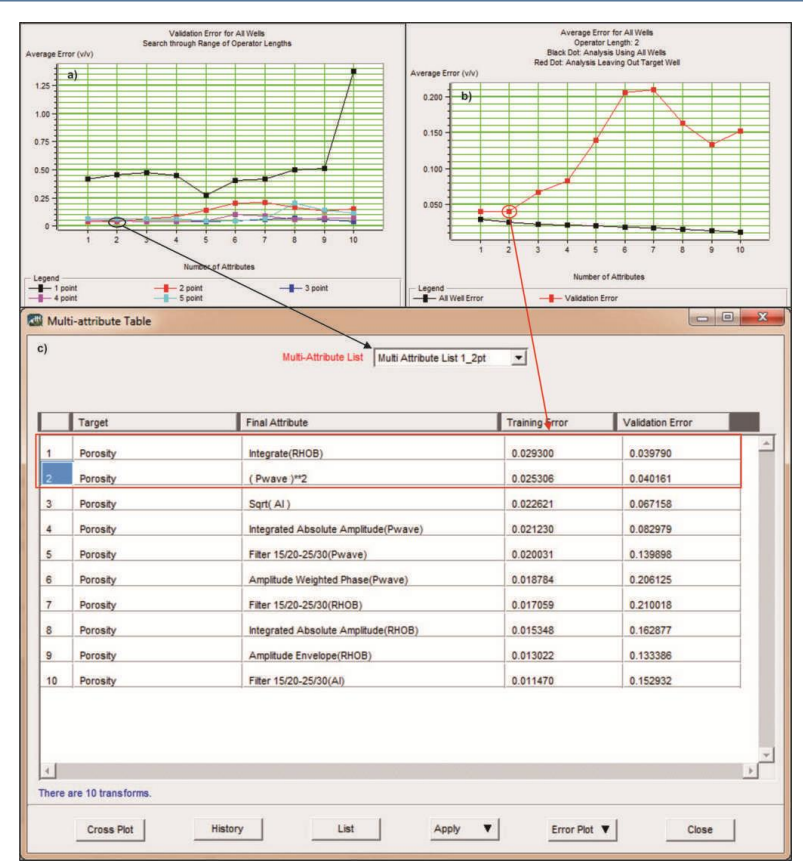

Gambar 8: a) Grafik validasi error, b) Grafik error rata-rata, dan c) Daftar atribut yang digunakan pada multiatribut porositas efektif.

Hasil training didapatkan nilai korelasi 0,649051 dan hasil validasi dengan nilai korelasi 0,5 (Gambar 9). Hasil korelasi muliatribut porositas sudah cukup baik dan bisa disebarkan ke cube seismik. Hasil yang tepat dapat dilakukan dengan melihat kesesuaian log dengan hasil multiatribut (Gambar 10).

\subsection{Model Reservoir}

Untuk menentukan karakteristik dan identifikasi reservoir pada daerah penelitian, dapat diperjelas dengan membuat peta-peta untuk mengetahui pola penyebarannya. Peta-peta tersebut dibuat dengan membuat slicing pada AI cube, gamma ray cube, dan porositas efektif cube. Penyebaran hidrokarbon dapat dilihat dengan membuat peta AI. Gambar 11 menunjukkan peta slicing hasil inversi AI. Pada gambar tersebut, daerah sumur FRD1 memiliki nilai AI yang rendah yaitu ditunjukkan dengan nilai $20.000-26.500((\mathrm{ft} / \mathrm{s}) /(\mathrm{g} / \mathrm{cc})$. Nilai AI yang rendah diinterpretasikan mengandung hidrokarbon.

Hasil dari multiatribut gamma ray juga dapat dibuat peta slicing gamma ray. Seperti dilihat dari Gambar 12 daerah sumur FRD1 memiliki nilai gamma ray 


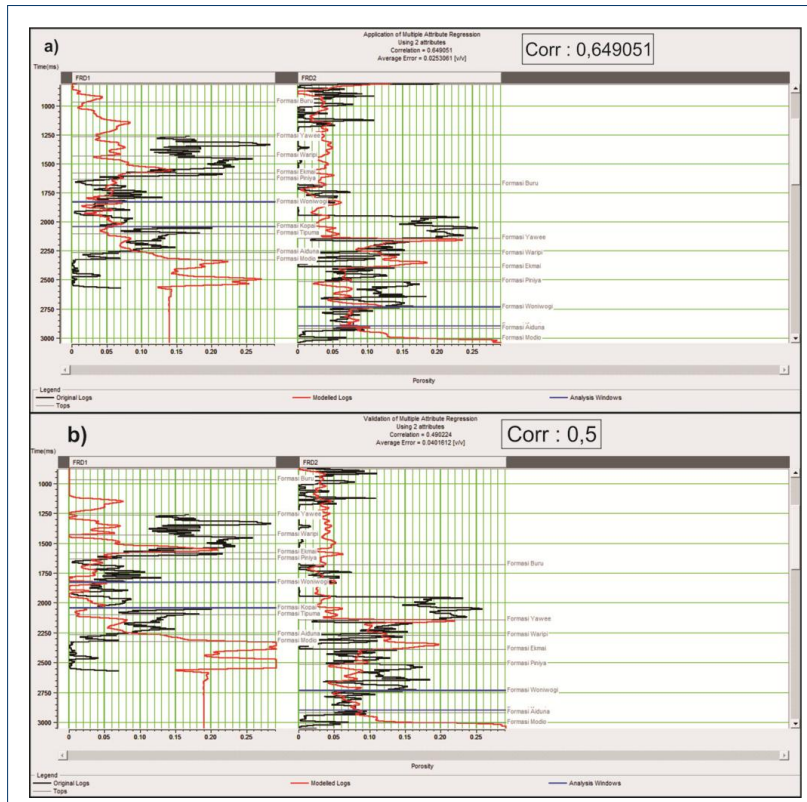

Gambar 9: Hasil training dan validasi.

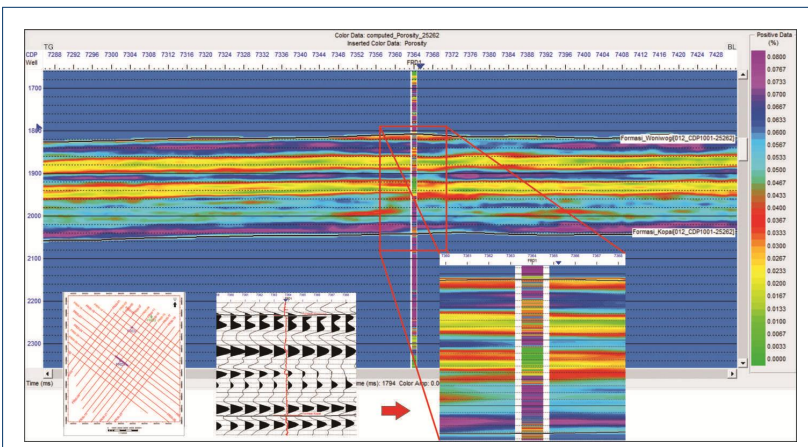

Gambar 10: Hasil validasi penyebaran multiatribut porositas efektif dengan nilai $\log$ porositas efektif.

yang rendah sampai sedang. Hal ini ditunjukkan dengan nilai gamma ray yaitu 60 API. Namun terdapat juga beberapa daerah dengan nilai gamma ray yang tinggi. Peta multiatribut yang lain yaitu peta porositas. Seperti dilihat dari Gambar 13 daerah sumur FRD1 memiliki nilai porositas yang tinggi. Hal ini ditunjukkan dengan nilai porositas yaitu $0,06-0,08 \mathrm{v} / \mathrm{v}$. Nilai porositas yang tinggi berpotensi mengandung hidrokarbon.

\section{KESIMPULAN}

Kesimpulan dari penelitian ini yaitu karakteristik reservoir pada daerah penelitian, Formasi Woniwogi pada FRD1 tersusun oleh litologi batupasir dan batuserpih, mempunyai nilai impedansi akustik
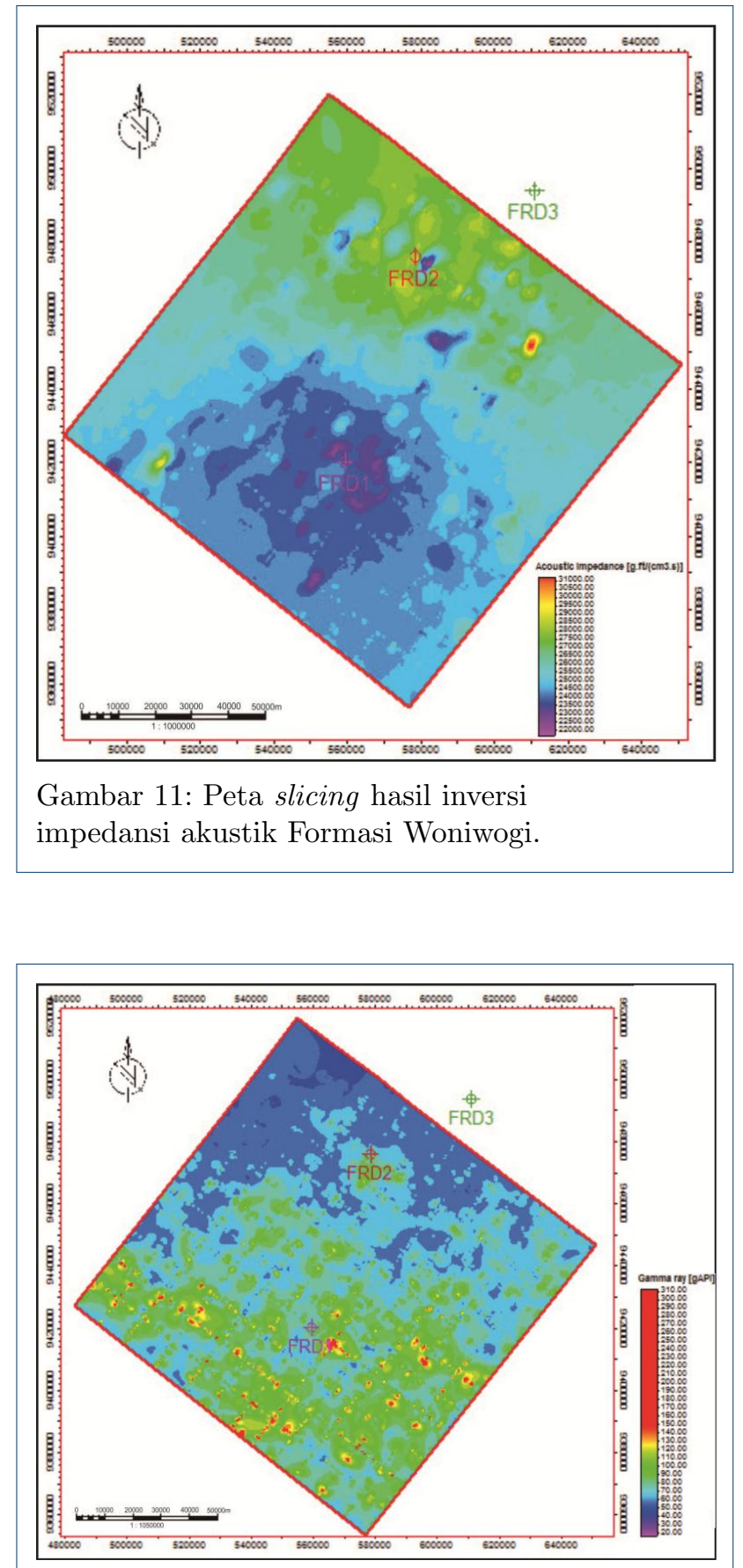

Gambar 12: Peta slicing hasil multiatribut gamma ray Formasi Woniwogi.

rendah, nilai gamma ray yang rendah - sedang, dan nilai porositas efektif yang tinggi. Zona prospek penelitian berada pada batupasir Formasi Woniwogi, sumur FRD1. 


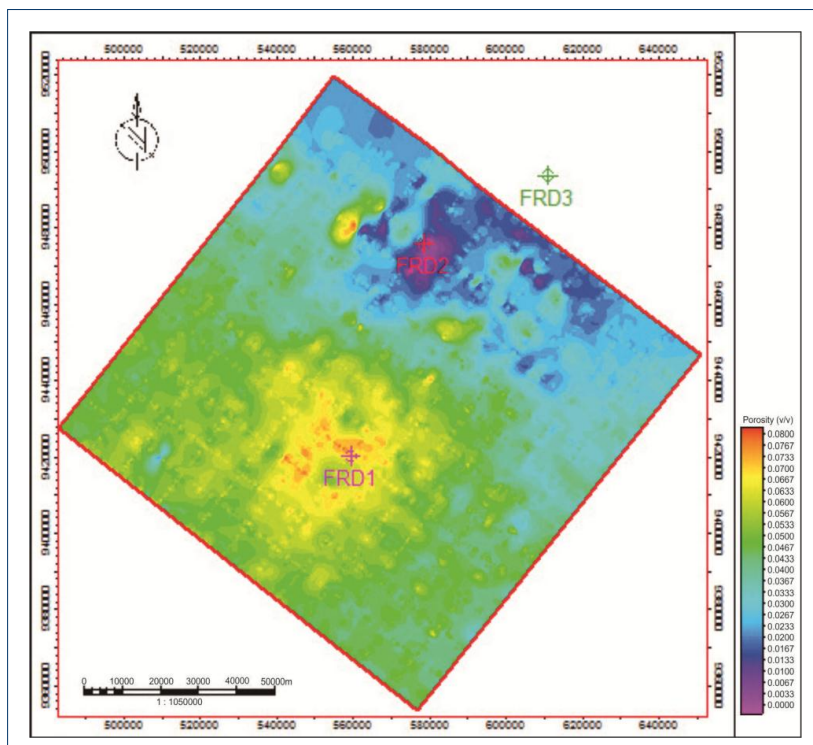

Gambar 13: Peta slicing hasil multiatribut porositas efektif Formasi Woniwogi.

\section{PENULIS}

1 Fitri Rusmaladewi

Dari :

(1) Departemen Teknik Geologi, Fakultas Teknik, Universitas Gadjah Mada

2 Sugeng Sapto Surjono

Dari :

(1) Departemen Teknik Geologi, Fakultas Teknik, Universitas Gadjah Mada

\section{Djoko Wintolo}

Dari :

(1) Departemen Teknik Geologi, Fakultas Teknik, Universitas Gadjah Mada

Pustaka

1. Iqbal D, Sugeng Sapto S. Pemodelan Reservoir dengan Menggunakan Metode Seismik Inversi pada Batupasir X, Formasi Woniwogi, Cekungan Akimeugah, Papua. Yogyakarta: Universitas Gadjah Mada; 2017.

2. Panggabean $\mathrm{H}$, Hakim AS. Reservoir rock potential of the Paleozoic-Mesozoic sandstone of the southern flank of the central range, Irian Jaya. 1986;p. $461-480$.

3. Sukmono S. Seismic Attributes For Reservoir Characterization. Bandung: Jurusan Teknik Geofisika Institut Teknologi Bandung; 2001.

4. Brown AR. Interpretation of three-dimensional seismic data. Society of Exploration Geophysicists and American Association of Petroleum Geologist; 2000. 